\title{
Osteopontin mRNA Is Expressed by Smooth Muscle-derived Foam Cells in Human Atherosclerotic Lesions of the Aorta
}

\author{
Tohru Ikeda, *" Takuji Shirasawa, ${ }^{*}$ Yukiyoshi Esaki, ${ }^{3}$ Shusaku Yoshiki," and Katsuiku Hirokawa * \\ Departments of * Pathology and ${ }^{\ddagger}$ Molecular Pathology, Tokyo Metropolitan Institute of Gerontology, and ${ }^{\S}$ Department of Pathology, \\ Tokyo Metropolitan Geriatric Hospital, Itabashi-ku, Tokyo 173, Japan; and "Department of Oral Pathology, \\ School of Dentistry, Showa University, Shinagawa-ku, Tokyo 142, Japan
}

\begin{abstract}
Osteopontin is a phosphorylated, sialic acid-rich, noncollagenous bone matrix protein containing the Arg-Gly-Asp-Ser amino acid sequence responsible for cell adhesion. The protein strongly binds to hydroxyapatite and play an important role in calcification. Expression of osteopontin mRNA was analyzed in human aortic atherosclerotic lesion by Northern blot hybridization, as well as by in situ hybridization. The expression of osteopontin mRNA was detected in 24 out of 25 samples of aorta obtained from 17 autopsy cases, but not in one normal aortic sample. The magnitude of expression was proportional to the stage of atherosclerosis. In situ hybridization revealed that the cells expressing osteopontin mRNA were detected in the wall surrounding atheroma and closely associated with calcification. They were morphologically identified as foam cells and immunohistologically positive with HHF35, appearing to be derived from smooth muscle cells. These findings have suggested that smooth muscle cell-derived foam cells express osteopontin mRNA and play an important role in calcification of the atherosclerotic lesions. (J. Clin. Invest. 1993. 92:2814-2820.) Key words: osteopontin • atherosclerosis • aorta $\bullet$ foam cells $\bullet$ human
\end{abstract}

\section{Introduction}

Osteopontin is a 44-kD acidic, sialated, phosphorylated glycoprotein purified from bone $(1,2)$, and it is known to be one of several noncollagenous bone matrix proteins. The cDNA has been cloned from a rat osteosarcoma cell line, ROS17/2.8 (3). Sequence analysis has revealed that it contains the Arg-GlyAsp-Ser amino acid sequence found in fibronectin and a number of other extracellular proteins recognized by the integrin superfamily (4). Subsequently, cDNA for a protein called $2 \mathrm{ar}$ was cloned from the mouse JB6 epidermal cell line $\mathrm{C} 122$ after treatment with 12-O-tetradecanoyl-phorbol-13-acetate (5). It was subsequently established that $2 \mathrm{ar}$ is the murine homologue of rat osteopontin $(5,6)$.

Osteopontin mRNA was detected in several organs, and its presence was especially strong in developing bones, kidney, and gall bladder (7-13). In developing bones, osteopontin

Address correspondence to Tohru Ikeda, Department of Pathology, Tokyo Metropolitan Institute of Gerontology, 35-2, Sakaecho, Itabashi-ku, Tokyo 173, Japan.

Received for publication 12 November 1992 and in revised form 2 August 1993.

J. Clin. Invest.

(C) The American Society for Clinical Investigation, Inc.

0021-9738/93/12/2814/07 \$2.00

Volume 92, December 1993, 2814-2820
mRNA is expressed in osteoblastic cells (10), and we found recently that in adult rat bones, osteopontin mRNA was expressed in osteocytes, osteoclasts, and acid phosphatase-positive mononuclear cells on the bone resorption surface, but not in osteoblasts (12). In the kidney, osteopontin is expressed in the tubules of the cortex and in loops of Henle (10).

Atherosclerosis is a common arterial disease in the middle aged and elderly, and most of advanced atherosclerotic lesions are accompanied by calcification. The mechanism of calcification in the atherosclerotic lesions remains unclear. However, some noncollagenous bone matrix proteins may be associated with the induction of aortic calcification because they are thought to influence the local mechanism of calcification (14). In fact, mRNA of osteopontin (one of bone matrix proteins) is detected in the kidney, where calcification often occurs. Thus, in the present study, the expression of osteopontin mRNA in atherosclerotic lesions of the human aorta was surveyed by in situ hybridization and Northern blot hybridization, and immunohistological analysis was performed to characterize the cells expressing osteopontin mRNA.

\section{Methods}

Tissue samples. For in situ hybridization, 17 samples were obtained from aortic arch, thoracic and abdominal aorta of 13 autopsy cases ranging in age from 62 to $90 \mathrm{yr}$. Postmortem intervals ranged from 1 to $18 \mathrm{~h}$. All the samples excised were fixed for $24 \mathrm{~h}$ at $4^{\circ} \mathrm{C}$ with $4 \%$ paraformaldehyde in $0.1 \mathrm{M}$ phosphate buffer containing $0.1 \%$ diethyl pyrocarbonate (Sigma Immunochemicals, St. Louis, MO) and processed for paraffin section. For Northern blot analysis, aortic specimens were obtained from four additional autopsy cases ranging in age from 76 to $83 \mathrm{yr}$ with clearly demarcated atherosclerotic lesions. A segment of thoracic or abdominal aorta was divided into two portions, putatively normal aorta and atherosclerotic lesion, and they were separately frozen in liquid nitrogen.

Microscopic analysis. Paraffin sections were stained with hematoxylin eosin and atherosclerotic lesions were classified into fibro-fatty lesions, fibrous plaques, and advanced plaques according to the report by Gown, Tsukada, and Ross (15). In 17 samples, there were 12 fibrofatty lesions, 5 fibrous plaques, and 5 advanced plaques, and all these lesions were examined by in situ hybridization.

In situ hybridization. $\left[{ }^{35} \mathrm{~S}\right] \mathrm{UTP}$-labeled single-stranded antisense and sense riboprobes for rat and human osteopontin $(3,16)$ cloned into pSPT 18 were transcribed by SP6 or T7 RNA polymerase using a transcription kit (SP6 / T7 Boehringer Mannheim GmbH, Mannheim, Germany). The $\left[{ }^{35} \mathrm{~S}\right] \mathrm{UTP}$-labeled probes were used for hybridization at a concentration of $1 \times 10^{4} \mathrm{cmp} / \mu 1$ in $50 \%$ formamide, $10 \%$ dextran sulfate, $0.6 \mathrm{M} \mathrm{NaCl}, 10 \mathrm{mM}$ Tris- $\mathrm{HCl}$ (pH 7.6), $1 \mathrm{mM}$ EDTA, $1 \times$ Denhardt's solution, $0.25 \%$ SDS, $10 \mathrm{mM} \mathrm{DTT}$, and $0.2 \mathrm{mg} / \mathrm{ml}$ transfer RNA. Treatment of the slides and hybridization conditions were the same as described previously $(10,12,17)$. Briefly, after dewaxing with xylene, the sections were rehydrated, fixed again for $15 \mathrm{~min}$ with the same fixative as described above, treated with $0.25 \%$ acetic anhydride in $0.1 \mathrm{M}$ triethanolamine $\mathrm{HCl}(\mathrm{pH} 8.0)$ for $10 \mathrm{~min}$, dehydrated in 


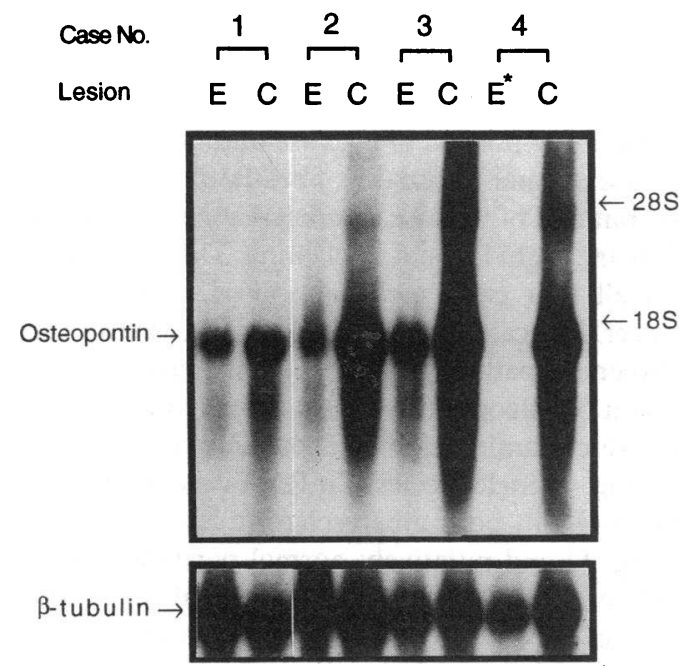

Figure 1. Northern blot hybridization of osteopontin mRNA in human aorta. Osteopontin mRNA expression in advanced calcified atherosclerotic lesions or early atherosclerotic lesions of the aorta. 20 $\mu \mathrm{g}$ of RNAs isolated from calcified atherosclerotic lesions $(C)$, early atherosclerotic lesion $(E)$, or putatively normal part $\left(E^{*}\right)$ of the aorta in four autopsy cases were separated in $1.2 \%$ formaldehyde-agarose gel, transferred to Hybond $\mathrm{N}$ membranes, hybridized with rat osteopontin cDNA probe (upper panel) or human $\beta$-tubulin probe (lower panel) for control hybridization.
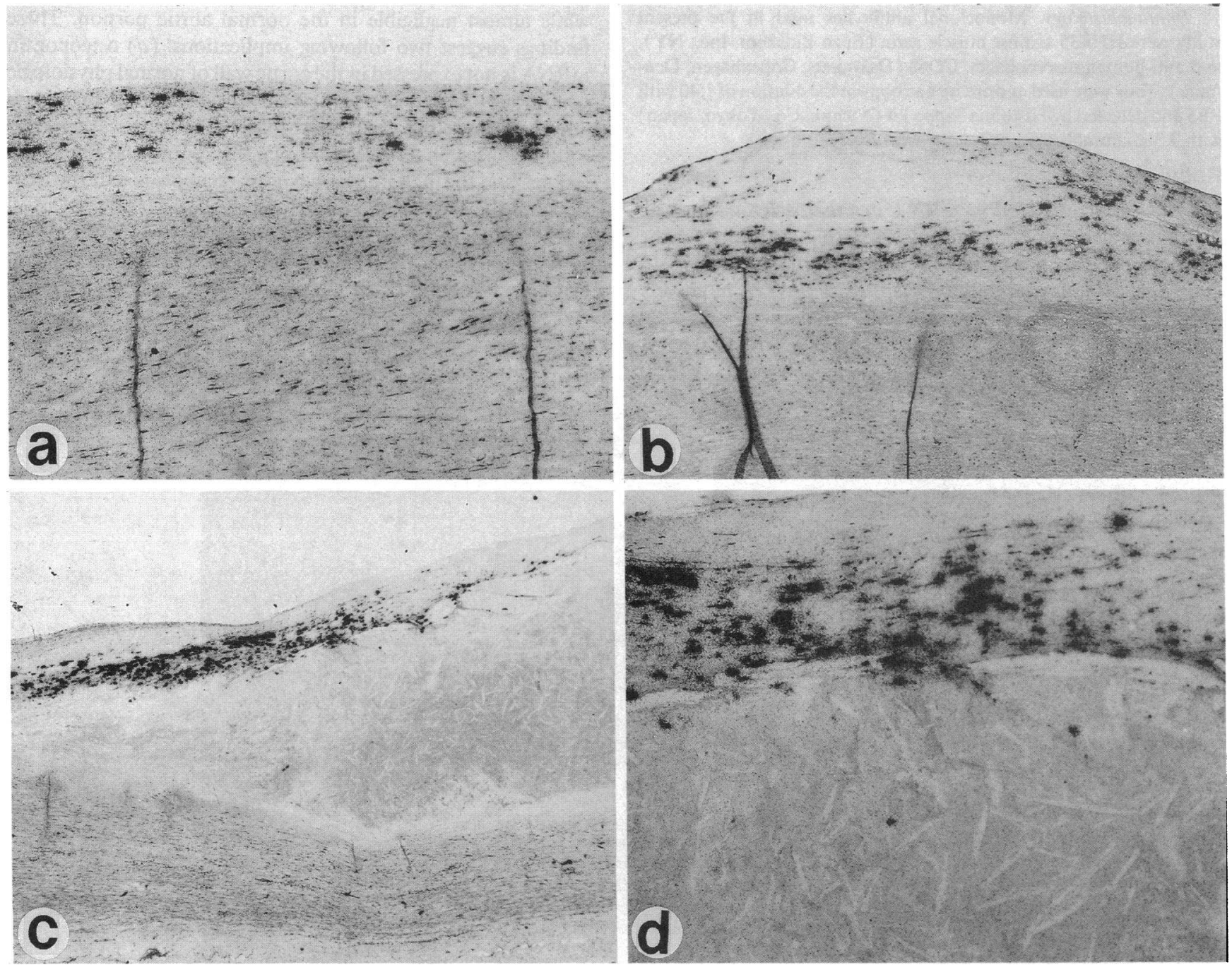

Figure 2. In situ hybridization of osteopontin mRNA in atherosclerotic lesions of human aorta. (a) Scattered presence of cells expressing osteopontin mRNA in the diffusely thickened intima. $\times 75$. (b) A fibrous plaque surrounded by osteopontin mRNA positive cells. $\times 40$. (c) Dense accumulation of positive cells in the wall covering an advanced atheromatous plaque. $\times 20$. $(d)$ Higher magnification of $(c)$ showing many positive cells in the wall, but a few in the atheromatous debris. $\times 75$. 
ethanol, and dried in air. The hybridization solution was spread over the sections, and the slides were incubated overnight at $50^{\circ} \mathrm{C}$ in plastic humidified boxes. After hybridization, the sections were washed twice in $50 \%$ formamide solution containing $2 \times$ SSC and $50 \mathrm{mM}$ DTT at $50^{\circ} \mathrm{C}$ for $30 \mathrm{~min}$. Then, the sections were washed twice in $2 \times \mathrm{SSC}$ and twice in $0.2 \times \mathrm{SSC}$ at $50^{\circ} \mathrm{C}$ for $30 \mathrm{~min}$. They were then dehydrated in ethanol and dipped in NTB-3 emulsion (Eastman Kodak, Rochester, NY) diluted 1:1 with $2 \%$ glycerol solution. The dipped slides were placed on ice-cold plate for $15 \mathrm{~min}$, dried at room temperature for $3 \mathrm{~h}$, and exposed at $4^{\circ} \mathrm{C}$ in desiccated slide boxes for $3 \mathrm{wk}$. The exposed slides were developed in D-19 developer at $20^{\circ} \mathrm{C}$ for $10 \mathrm{~min}$. They were counterstained with hematoxylin and eosin.

Northern blot hybridization. Northern blot analysis: total RNAs were isolated from frozen aortic tissues by single-step acid quanidine phenol chloroform method (18). $20 \mu \mathrm{g}$ of the isolated RNAs were electrophoresed in a $1.2 \%$ agarose-formaldehyde gel, and blotted onto membranes (Hybond N; Amersham International, Amersham, United Kingdom). The membranes were hybridized with ${ }^{32} \mathrm{P}$-labeled cDNA probe at $65^{\circ} \mathrm{C}$ in a rapid hybridization buffer (Amersham International ), washed in $0.2 \times \mathrm{SSC}$ buffer containing $0.1 \% \mathrm{SDS}$ at $65^{\circ} \mathrm{C}$, and exposed to Kodak XRP-5 film with lightening (Cronex; DuPont Pharmaceutical, Inc., Wilmington, DE) plus intensifying screen. cDNA probes used were those for human osteopontin (16) and human $\beta$-tubulin.

Immunohistology. Monoclonal antibodies used in the present study were HHF35 against muscle actin (Enzo Biochem, Inc., NY), and anti-human macrophages, CD68 (Dakopatts, Copenhagen, Denmark). They were used as primary antibody at the dilution of $1: 40$ with PBS and detected by Histofine Sappo kit (Nichirei Co., Tokyo, Japan) with 3,3'-diaminobenzidine tetrahydrochloride.

\section{Results}

Expression of osteopontin $m R N A$ in atherosclerotic lesions. Aortic samples from four autopsy cases were examined for the expression of osteopontin mRNA by Northern blot analysis. In these selected four cases, atherosclerotic lesions and putatively normal portions were rather easily distinguishable by naked eyes, and could be separately examined and compared in the same individual. Histological examination revealed that the putatively normal aortic portion of the case numbers 1,2 , and 3 contained diffuse intimal thickening, fibro-fatty lesions, and fibrous plaques, but that of the case number 4 appeared almost normal, just showing slight intimal thickening. The atherosclerotic lesions of all four cases were composed of advanced plaques with ulcer and calcification in places. To clarify the association between the pathological changes of atherosclerosis and the expression of osteopontin, RNAs extracted from four pairs of samples were examined for the expression of osteopontin. As shown in Fig. 1, single species of mRNA was detected by rat osteopontin probe in both atherosclerotic lesions (designated as $C$ in Fig. 1) and putatively normal portions (designated as $E$ ), but not in RNA prepared from normal aortic wall of case 4 ( $E^{*}$ in Fig. 1$)$. It is interesting to note that the expression of osteopontin mRNA was always greater in the atherosclerotic lesions with calcification $(C)$ than in the putatively normal portions $(E)$, although the extent of expression varied from case to case. Above all, in case 4, the expression of osteopontin mRNA was very strong in the atherosclerotic lesion, while almost negligible in the normal aortic portion. These findings suggest two following implications: $(a)$ osteopontin mRNA is not expressed in the aortic wall of normal physiologic condition; and $(b)$ the expression of osteopontin mRNA is already observed in the aortic wall having earlier atherosclerotic lesions such as diffuse intimal thickening and fibro-fatty lesions, and the magnitude of expression appears to be proportional to the stage of atherosclerosis.

Distribution of osteopontin $m R N A$ in atherosclerotic lesions. The expression of osteopontin mRNA by in situ hybridization was examined in 17 atherosclerotic lesions, 12 fibro-

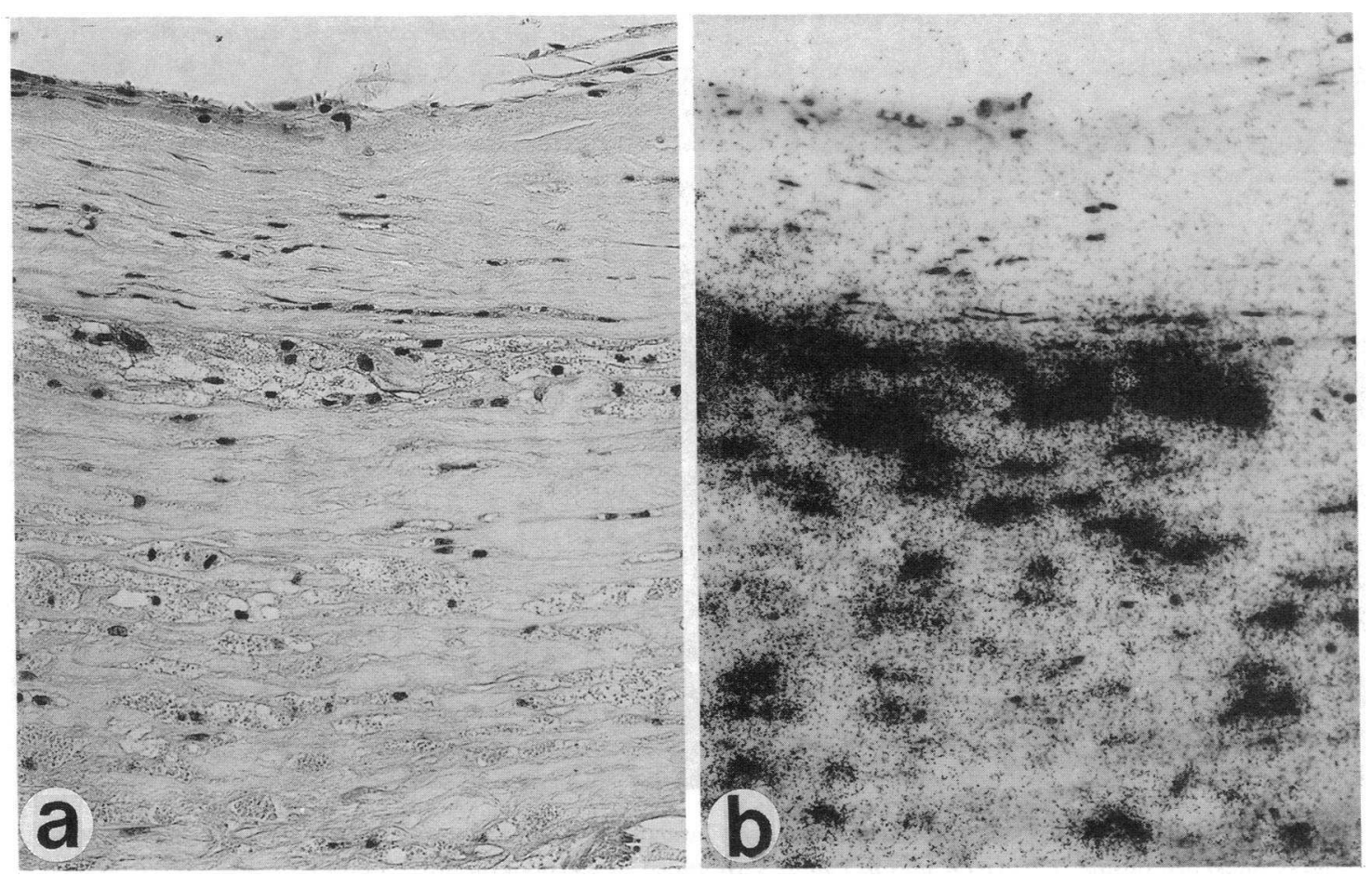

Figure 3. Comparison of HE $(a)$ and in situ hybridization of osteopontin mRNA $(b)$ in two serial sections. Presence of numerous large foam cells in the wall covering atheromatous plaque $(a)$, and many of them expressing osteopontin mRNA $(b) . \times 240$. 
fatty lesions, 5 fibrous plaques, and 5 advanced plaques. The expression was observed in all 22 lesions analyzed. The hybridization signal for osteopontin mRNA was closely associated with the stage of atherosclerosis. Osteopontin mRNA positive cells were scattered in the thickened intimal layer of fibro-fatty lesions of the aorta (Fig. $2 a$ ). In fibrous plaques, hybridization signals were detected around the fibrous mass (Fig. $2 b$ ). In advanced plaques, hybridization signals were seen in the wall around atheromatous debris (Fig. 2, $c$ and $d$ ), apparently increasing in number and intensity as compared with atherosclerotic lesions of earlier stage. At higher magnification of serial neighboring sections, the cells expressing osteopontin mRNA were identified to be foam cells (Fig. $3 a$ and $b$ ).

To see the relationship between the expression of osteopontin mRNA and deposition of calcium, the adjacent section of that used for in situ hybridization was stained with von Kossa method. It was revealed that deposition of calcium and hybridization signals were not seen in exactly the same site, but seen side by side, closely associated with each other (Fig. 4, $a$ and $b$ ).

Immunohistological identification of the cells expressing osteopontin $m R N A$. Foam cells in atheromatous lesions could be either macrophages or smooth muscle-derived cells. To identify which type of cells were expressing osteopontin mRNA, two serial adjacent sections were immunohistologically stained with either HHF35 recognizing smooth muscle antigen or anti-CD68 antibody recognizing human macrophage. Generally, two types of cells were intermingled in many places so that it was not easy to determine which types of cells, HHF35- or CD68-positive cells, were expressing osteopontin mRNA. Nevertheless, there were several places where they were distributed in different places, or only one type of cells was seen. Fig. $5 a-c$ are a set of three serial sections, where HHF35-positive cells (Fig. $5 a$ ) and CD68-positive cells (Fig. 5 c) are distributed in different layers of the thickened intima; the former are in the upper and middle layers, and the latter are in the bottom layer. The cells expressing osteopontin mRNA are distributed in the middle layer (Fig. $5 \mathrm{~b}$ ), and the pattern of distribution is almost identical to that of HHF35-positive cells. Fig. $5 d-f$ are another set of three serial sections including atheroma, where only HHF35-positive cells (Fig. $5 d$, arrows), but a few CD68-positive cells (Fig. $5 f$ ), are seen in the wall of atheroma. In this case also, the cells expressing osteopontin mRNA (Fig. $5 e$ ) are seen in the same place where HHF35-positive cells are present. Fig. $6 a$ shows one place where only CD68-positive foam cells are present in atheromatous debris, but no HHF35-positive cells (data, not shown). In an adjacent section examined by in situ hybridization, however, there are no cells expressing osteopontin mRNA (Fig. $6 \mathrm{~b}$ ). In this regard, we could not rule out the possibility that the absence of HHF35 staining in the atheromatous debris is caused by the alteration of its epitope beyond antibody recognition in the unusual physicochemical microenvironment of the necrotic core.

These findings taken together have suggested that foam cells expressing osteopontin mRNA in the atherosclerotic lesions are smooth muscle-derived cells.

\section{Discussion}

The present study has indicated that smooth muscle-derived foam cells express osteopontin mRNA in the atherosclerotic lesions of the aorta, and the magnitude of expression increases
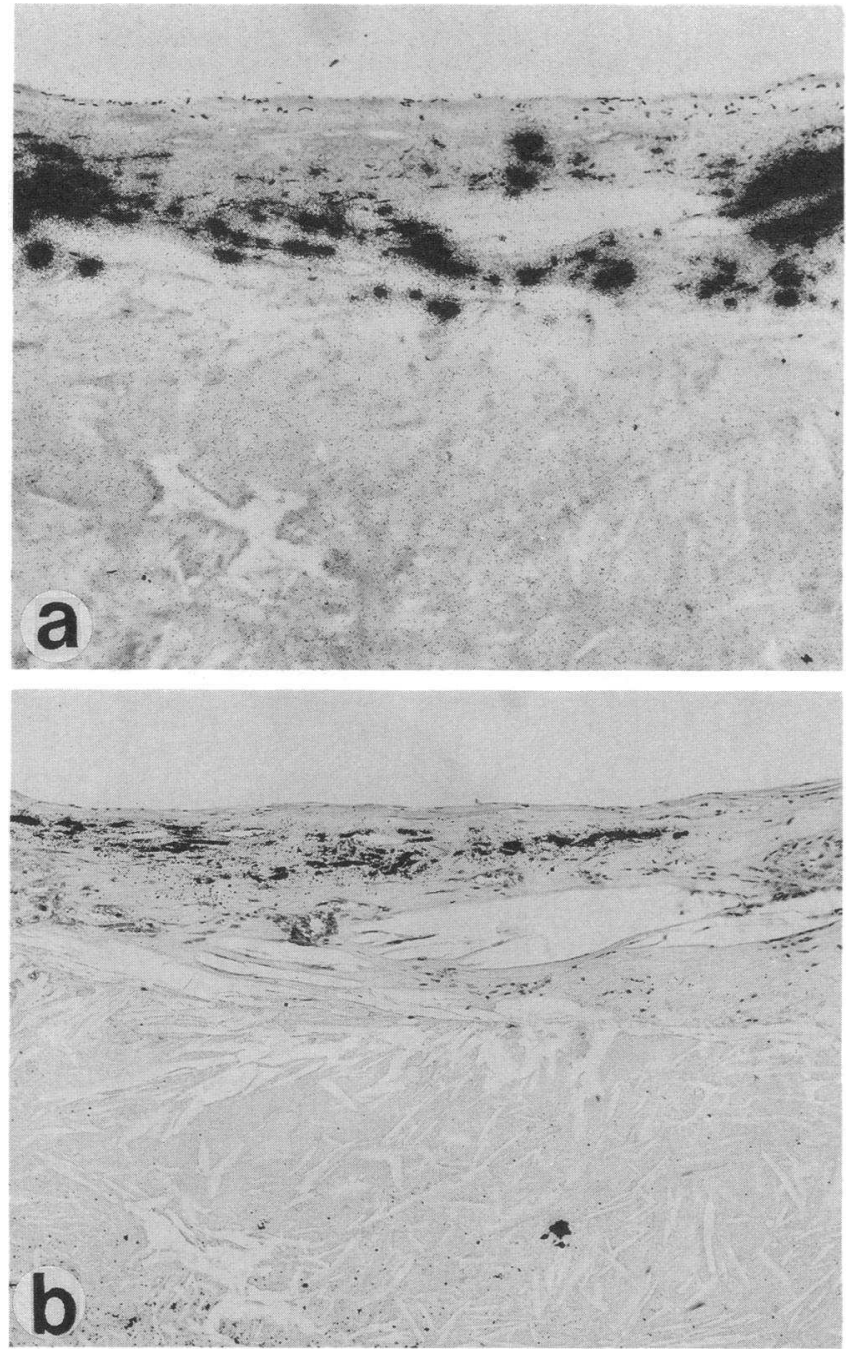

Figure 4. Comparison of in situ hybridization of osteopontin mRNA and von Kossa staining. ( $a$ ) Strong expression of hybridization signals is seen in the tissue covering an atheromatous debris. (b) An adjacent section of $(b)$ stained with von Kossa methods to see the distribution of calcium deposits. The calcium deposits are seen in close association with the sites where hybridization signals are present, but not in the same place. $\times 75$.

in proportion to the stage of atherosclerosis. Regarding the expression of osteopontin mRNA in the aorta, Giachelli et al. (19) investigated rat aorta and reported that osteopontin mRNA was detected in the aorta and carotid, and the expression in the latter was enhanced after injury. In the human aorta, however, we have shown that osteopontin mRNA is not detected in an almost normal aorta by Northern blot analysis, and that by in situ hybridization, the expression of osteopontin mRNA was not seen in normal smooth muscle cells in the media. In this respect, Brown et al. (13) reported that there was no evidence of osteopontin transcript in association with smooth muscle of the various organs, and this report is consistent with ours. The enhanced expression of osteopontin mRNA in rat carotid after injury may be consistent with the present finding that the osteopontin expression is detected in the atherosclerotic lesions, but not in normal portion.

Osteopontin is one of the noncollagenous proteins in bone matrix, and is known to be produced in osteoblasts in develop- 

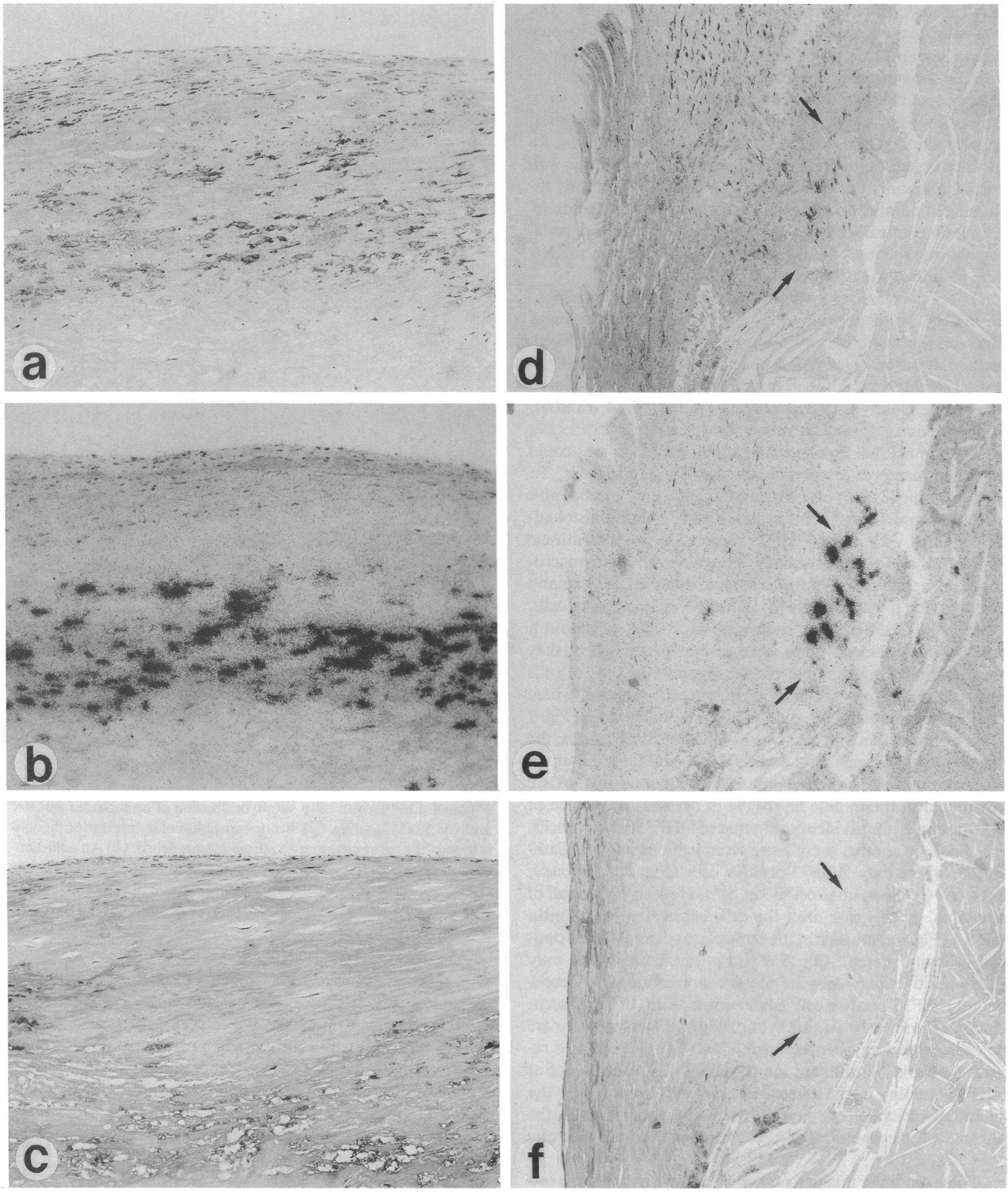

Figure 5. Immunohistological staining of HHF35 (anti-smooth muscle antigen) and CD68 (anti-human macrophages), and in situ hybridization of osteopontin mRNA in three serial sections $(a-c$ and $d-f)$. (a) HHF35 staining of an atherosclerotic lesion. Zonal distribution of positive cells in the subendothelial layer and the middle layer: The cells in the middle layer are larger than those in the subendothelial layer. $(b)$ In situ hybridization of osteopontin mRNA. Positive cells are seen in the middle layer. (c) CD68 staining, showing positive cells in the bottom layer and a few in the middle layer. $(d)$ HHF35 staining of an atheromatous plaque. Positive cells are scattered in the wall covering atheromatous debris. (e) Focal accumulation of the cells expressing osteopontin mRNA. $(f)$ A few CD68-positive cells in the lower part of the photomicrograph. Arrows indicate the corresponding site where cells expressing osteopontin mRNA are present. $\times 100$. 

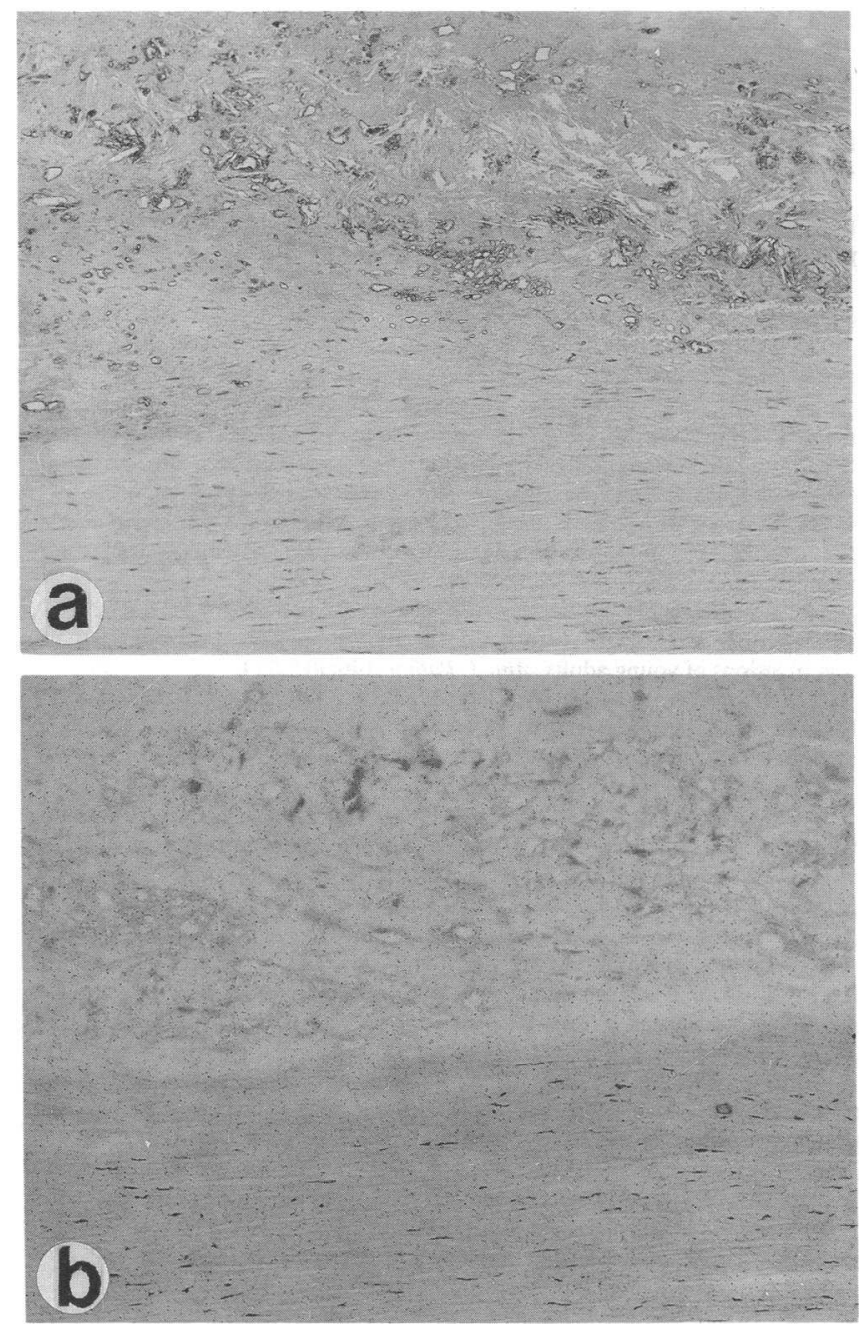

Figure 6. In situ hybridization of osteopontin mRNA. (a) Presence of numerous CD68-positive cells in atheromatous lesion in the upper half. The lower half is the media. $\times 100$. $(b)$ In situ hybridization of osteopontin mRNA performed on an adjacent section. Positive cells are not seen. $\times 100$.

ing bone (7). The function of osteopontin is still not fully understood in the bone tissue, although it contains the Arg-GlyAsp-Ser adhesion molecule identical to that of fibronectin (4), which is suggested to be involved in cell attachment $(7,20)$. However, the findings in the present study have suggested that the expression of osteopontin is associated with the calcification that frequently occurs in advanced stages of atherosclerosis of the aorta. In bone tissue, calcification is known to initiate in small vesicular structures termed "matrix vesicles," where hydroxyapatite crystals are detected (21). It is interesting to note that the same "matrix vesicles" were found in the atherosclerotic lesions (22). Furthermore, Tanimura et al. (23) reported that matrix vesicles found in the atherosclerotic lesions were derived from smooth muscle cells. Therefore, it is suggested that calcium deposition in atherosclerotic lesions is initiated in matrix vesicle derived from smooth muscle cells. This hypothesis is strongly supported by our present findings that osteopontin mRNA was detected in smooth muscle-derived foam cells in the atherosclerotic lesions of aorta, and that calcium deposits were seen in the area around these cells. These findings, including ours, are compatible with each other because osteopontin has strong capacity to bind hydroxyapatite $(3,7)$. It is of considerable interest that osteopontin mRNA is detectable not only in bones, but also in the kidney and aorta. Both the kidney and aorta are known to be sites where heterotopic calcification often occurs. Osteopontin was reported to play a role in the formation of urinary stone (24). These findings, together with our present data, have suggested that osteopontin is associated with not only bone metabolism, but also pathological calcification in other organs. In this respect, it is interesting to note that bone morphogenetic protein-2a was found to be expressed in calcified human atherosclerotic plaque (25). Elucidation of the precise mechanism of calcification in the atherosclerotic lesion of the aorta and branching arteries would be an important approach to understand the process of atherosclerosis, and this should include more extensive study on the expression of osteopontin and bone morphogenetic protein-2a in the atherosclerotic lesions.

Origin of foam cells in human atherosclerotic lesions was examined immunohistologically using HHF35 (anti-smooth muscle) and HAM56 (anti-human macrophages) antibodies, and they were reported to be derived from either smooth muscle cells or macrophages $(15,26)$. Gown et al. (15) reported that foam cells expressed either HHF35 or HAM56, and never both of these. In practice, both types of foam cells are intermingled in most places of atherosclerotic lesions. But the question is which type of cells express osteopontin mRNA in atherosclerotic lesions. By careful examination, however, it is possible to find sites where both types of foam cells are distributed in different places, or only one type of foam cells are present. In the present study, we extensively searched for such places and found that the cells expressing osteopontin mRNA are HHF35 positive and appear to be derived from smooth muscle cells. To confirm this finding, more skillful examination using double or triple immunohistological staining would be required.

Expression of various kinds of molecules were reported to be present in atherosclerotic lesions; i.e., stromelysin (27), lipoprotein lipase (28), apolipoprotein E (29), and macrophage colony-stimulating factor $(30,31)$. All of these have been considered to be expressed by both smooth muscle cells and macrophages, and functional similarity has been suggested between them.

In the present study, we have focused on the finding that the cells expressing osteopontin mRNA are present in the atherosclerotic lesions and may play an important role in calcification of the aorta.

\section{Acknowledgments}

Authors wish to express their appreciation to Dr. Shintaro Nomura (Department of Pathology, Osaka University Medical School) for his help to perform in situ hybridization.

\section{References}

1. Franzen, A., and D. Heinegard. 1985. Isolation and characterization of two sialoproteins present only in bone calcified matrix. Biochem. J. 232:715-724.

2. Prince, C. W., T. Oosawa, W. T. Butler, M. Tomana, A. S. Bhown, M. Bhown, and R. E. Schrohenloher. 1987. Isolation, characterization, and biosynthesis of a phosphorylated glycoprotein from rat bone. J. Biol. Chem. 262:29002907.

3. Oldberg, A., A. Franzen, and D. Heinegard. 1986. Cloning and sequence analysis of rat bone sialoprotein (osteopontin) cDNA reveals an Arg-Gly-Asp cell-binding sequence. Proc. Natl. Acad. Sci. USA 83:8819-8823. 
4. Ruoslahti, E. 1988. Fibronectin and its receptors. Annu. Rev. Biochem. 57:375-413.

5. Smith, J. H., and D. T. Denhardt. 1987. Molecular cloning of a tumor promoter-induced mRNA found in JB6 mouse epidermal cells: induction is stable at high, but not at low, cell densities. J. Cell. Biochem. 34:13-22.

6. Craig, A. M., J. H. Smith, and D. T. Denhardt. 1989. Osteopontin, a transformation-associated cell adhesion phosphoprotein, is induced by $12-O$-tetradecanoylphorbor 13-acetate in mouse epidermis. J. Biol. Chem. 264:96829689.

7. Butler, W. T. 1989. The nature and significance of osteopontin. Connect. Tissue Res. 23:123-136.

8. Yoon, K., R. Buenaga, and G. A. Rodan. 1987. Tissue specificity and developmental expression of rat osteopontin. Biochem. Biophys. Res. Commun. 148:1129-1136.

9. Mark, M. P., C. W. Prince, T. Oosawa, S. Gay, A. L. J. J. Bronckers, and W. T. Butler. 1987. Immunohistochemical demonstration of a 44-KD phosphoprotein in developing bones. J. Histochem. Cytochem. 35:707-715.

10. Nomura, S., A. Willis, D. R. Edwards, J. K. Heath, and B. L. Hogan. 1988. Developmental expression of 2ar (osteopontin) and SPARC (osteonectin) RNA as revealed by in situ hybridization. J. Cell Biol. 106:441-450.

11. Weinreb, M., D. Shinar, and G. A. Rodan. 1990. Different pattern of alialine phosphatase, osteopontin, and osteocalcin expression in developing rat bone visualized by in situ hybridization. J. Bone Miner. Res. 5:831-842.

12. Ikeda, T., S. Nomura, A. Yamaguchi, T. Suda, and S. Yoshiki. 1992. In situ hybridization of bone matrix proteins in undecalcified adult rat bone sections. J. Histochem. Cytochem. 40:1079-1088.

13. Brown, L. F., B. Berse, L. Van de Water, A. Papadopoulos-Sergiou, C. A Perruzzi, E. J. Manseau, H. E. Dvorak, and D. R. Senger. 1992. Expression and distribution of osteopontin in human tissues: widespread association with luminal epithelial surfaces. Mol. Biol. Cell. 3:1169-1180.

14. Fisher, L. W., and J. D. Termine. 1985. Noncollagenous proteins influencing the local mechanisms of calcification. Clin. Orthopaed. Rel. Res. 200:362-385.

15. Gown, A. M., T. Tsukada, and R. Ross. 1986. Human atherosclerosis. II. Immunocytochemical analysis of the cellular composition of human atherosclerotic lesions. Am. J. Pathol. 125:191-207.

16. Kiefer, M. C., D. M. Bauer, and P. J. Barr. 1989. The cDNA and derived amino acid sequence for human osteopontin. Nucleic Acids Res. 17:3306.

17. Ingham, P. W., K. R. Howard, and D. Ish-Horowicz. 1985. Transcription of the drosophila segmentation gene haily. Nature (Lond.). 318:439-445.

18. Chomzynski, P., and N. Sacci. 1987. Single-step method of RNA isolation by acid guanidinium thiocyanate-phenol-chloroform extraction. Anal. Biochem. 162:156-159.

19. Giachelli, C., N. Bae, D. Lombardi, M. Majesky, and S. Schwartz. 1991.
Molecular cloning and characterization of 2B7, a rat mRNA which distinguishes smooth muscle cell phenotypes in vitro and is identical to osteopontin (secreted phosphoprotein I, 2aR). Biochem. Biophys. Res. Commun. 177:867-873.

20. Reinholt, F. P., K. Hultenby, A. Oldberg, and D. Heinegard. 1990. Osteopontin-a possible anchor of osteoclasts to bone. Proc. Natl. Acad. Sci. USA. 87:4473-4475.

21. Anderson, H. C. 1985. Matrix vesicle calcification: review and update. In Bone and Mineral Research. Vol. 3. W. A. Peck, editor. Elsevier Science Publishers, Amsterdam. pp. 109-149.

22. Kim, K. M. 1976. Calcification of matrix vesicles in human aortic valve and aortic media. Fed. Proc. 35:156-162.

23. Tanimura, A., D. H. McGregor, and H. C. Anderson. 1983. Matrix vesicles in atherosclerotic calcification. Proc. Soc. Exp. Biol. Med. 172:173-177.

24. Kohri, K., Y. Suzuki, K. Yoshida, K. Yamamoto, N. Amasaki, T. Yamate, T. Umekawa, M. Iguchi, H. Sinohara, and T. Kurita. 1992. Molecular cloning and sequencing of cDNA encoding urinary stone protein, which is identical to osteopontin. Biochem. Biophys. Res. Commun. 184:859-864.

25. Bostrom, K., K. E. Watson, S. Horn, C. Wortham, I. M. Herman, and L. L. Demer. 1993. Bone morphogenetic protein expression in human atherosclerotic lesions. J. Clin. Invest. 91:1800-1809.

26. Katsuda, S., H. C. Boyd, C. Fligner, R. Ross, and A. M. Gown. 1992. Human atherosclerosis. III. Immunohistochemical analysis of the cell composition of lesions of young adults. Am. J. Pathol. 140:907-914.

27. Henney, A. M., P. R. Wakeley, M. J. Davis, K. Foster, R. Hembry, G. Murphy, and S. Humphries. 1991. Localization of stromelysin gene expression in atherosclerotic plaques by in situ hybridization. Proc. Natl. Acad. Sci. USA 88:8154-8158.

28. Yla-Herttuala, S., B. A. Lipton, M. E. Rosenfeld, I. J. Goldberg, D. Steinberg, and J. L. Witztum. 1991. Macrophages and smooth muscle cells express lipoprotein lipase in human and rabbit atherosclerotic lesions. Proc. Natl. Acad. Sci. USA 88:10143-10147.

29. Salomon, R. T., R. Underwood, M. V. Doyle, A. Wang, and P. Libby. 1992. Increased apolipoprotein $\mathrm{E}$ and $\mathrm{c}-\mathrm{fms}$ gene expression without elevated interleukin 1 or 6 mRNA levels indicates selective activation of macrophage junctions in advanced human atheroma. Proc. Natl. Acad. Sci. USA 89:2814 2828.

30. Rosenfeld, M. E., S. Yla-Herttuala, B. A. Lipton, V. A. Ord, J. L. Witztum, and D. Steinberg. 1992. Macrophage colony-stimulating factor mRNA and protein in atherosclerotic lesions of rabbits and humans. Am. J. Pathol. 140:291300.

31. Clinton, S. K., R. Underwood, L. Hayes, M. L. Sherman, D. W. Kufe, and P. Libby. 1992. Macrophage colony-stimulating factor gene expression in vascular cells and in experimental and human atherosclerosis. Am. J. Pathol. 140:301316. 